\title{
Platelet function tests: a comparative review
}

This article was published in the following Dove Press journal:

Vascular Health and Risk Management

18 February 2015

Number of times this article has been viewed

\section{Rita Paniccia ${ }^{1,2}$ \\ Raffaella Priora ${ }^{1,2}$ \\ Agatina Alessandrello \\ Liotta $^{2}$ \\ Rosanna Abbate ${ }^{1,2}$ \\ 'Department of Experimental and Clinical Medicine, Thrombosis Center, University of Florence, Florence, Italy; ${ }^{2}$ Department of Heart and Vessels, Azienda Ospedaliero-Universitaria Careggi, Florence, Italy}

Correspondence: Rita Paniccia

Department of Experimental and Clinical Medicine, Thrombosis Center, University of Florence, Viale Pieraccini, 19, 50134 Florence, Italy

Tel +39055 7949419

Fax +39055 7949929

Email rita.paniccia@unifi.it
Abstract: In physiological hemostasis a prompt recruitment of platelets on the vessel damage prevents the bleeding by the rapid formation of a platelet plug. Qualitative and/or quantitative platelet defects promote bleeding, whereas the high residual reactivity of platelets in patients on antiplatelet therapies moves forward thromboembolic complications. The biochemical mechanisms of the different phases of platelet activation - adhesion, shape change, release reaction, and aggregation - have been well delineated, whereas their complete translation into laboratory assays has not been so fulfilled. Laboratory tests of platelet function, such as bleeding time, light transmission platelet aggregation, lumiaggregometry, impedance aggregometry on whole blood, and platelet activation investigated by flow cytometry, are traditionally utilized for diagnosing hemostatic disorders and managing patients with platelet and hemostatic defects, but their use is still limited to specialized laboratories. To date, a point-of-care testing (POCT) dedicated to platelet function, using pertinent devices much simpler to use, has now become available (ie, PFA-100, VerifyNow System, Multiplate Electrode Aggregometry [MEA]). POCT includes new methodologies which may be used in critical clinical settings and also in general laboratories because they are rapid and easy to use, employing whole blood without the necessity of sample processing. Actually, these different platelet methodologies for the evaluation of inherited and acquired bleeding disorders and/or for monitoring antiplatelet therapies are spreading and the study of platelet function is strengthening. In this review, well-tried and innovative platelet function tests and their methodological features and clinical applications are considered.

Keywords: platelets, method, point-of-care testing, laboratory assessment, bleeding, thrombosis

\section{Introduction}

Human platelets are critically involved in both normal hemostasis and pathological bleeding and thrombosis. These particular cells contribute greatly to vessel constriction and repair, host defense, and tumor growth/metastasis. ${ }^{1}$ In addition, platelets acting together with other cells - white, endothelial, or smooth muscle cells - play a part in inflammation, in related pathologies, and in the promotion of atherosclerosis. ${ }^{2-4}$ Notwithstanding this multiplicity of roles, the available platelet function tests explore principally the alterations directly related to the hemostatic process. ${ }^{5}$

Primary hemostasis consists of the interaction between platelets and vessel wall. At the site of damage of a vessel wall, platelets are rapidly engaged in a sequential functional response including various steps in platelet activation: adhesion, spreading, shape change, aggregation, release reaction, exposure of a procoagulant surface, 
and clot retraction. The rapid progression of these different capacities causes the activated platelets to form a hemostatic plug that occludes the site of injury to prevent blood loss. ${ }^{6}$ An increased risk of bleeding could be present when platelet count is reduced and/or one of their functions is defective. Conversely, improper thrombus formation could be due to a growth in platelet count or reactivity. In particular, activated platelets adhere and aggregate within atherosclerotic lesions, forming occluding arterial thrombi that may result in thromboembolic disease such as stroke or myocardial infarction, two of the major causes of morbidity and mortality in the Western world. , $^{4}$

These different functions of platelets may be reliably detected with a wide spectrum of tests. The inherited or acquired platelet dysfunctions have to be essentially diagnosed because a rapid identification of patients at risk of bleeding is really necessary; the monitoring of antiplatelet therapy is becoming increasingly important for the identification of hypo- or hyperresponder patients at risk of both thrombosis or hemorrhage; the management of perioperative hemostasis and the different aspects of platelet banking (concentrates, transfusions, and evaluation of donor platelet function) is of vital importance; and - last but not least - the physiopathology of platelets should be critically recognized by basic research with these tests. ${ }^{8,9}$

The history of platelet function testing (PFT) begins with the development of the evaluation of the bleeding time (BT) by the Duke procedure. ${ }^{10}$ This was the first test for the assessment of the capacity of platelets to form a plug. For many years, it has been the unique screening test to identify both congenital or acquired platelet disorders. ${ }^{11}$ In the $1960 \mathrm{~s}$, the revolutionary platelet aggregation test in plateletrich plasma (PRP) - ie, light transmission aggregometry (LTA) - according to Born's studies was the key method used to diagnose platelet function. ${ }^{12}$ In this test, the ability of platelets to aggregate to each other in response to external aggregating agents - agonists, such as adenosine-diphosphate (ADP), arachidonic acid (AA), collagen, and epinephrine (EPI) - is measured in vitro. ${ }^{13}$ Since the late 1980 s, other PFT methods, such as platelet aggregometry in whole blood (WB), the study of activated platelets ex vivo by flow cytometry, the measurement of specific compounds released by platelets, and the assessment of platelet nucleotides have become available. ${ }^{14-16}$ Hence, PFT has been narrowly employed for the diagnosis and management of patients suffering from hemorrhagic problems. ${ }^{17}$ In the last 2 decades, the clinical application of PFT has improved as it has increasingly come to be used for monitoring the antiplatelet treatment of cardiovascular patients at risk of arterial disease ${ }^{18}$ However, the increasing number of patients on antiplatelet drugs, with a higher risk of bleeding, especially during trauma and surgical procedures, has also led to the emergence of PFT as a useful tool in presurgical/perioperative settings for the prediction of hemorrhage and for monitoring the efficacy of different prohemostatic therapies. In this scenario, the development of new, simpler instruments for assessing platelet function at the point-of-care (POC) or bedside has led to better prospects of using PFT not only in specialized clinical or research laboratories, but also in general laboratories and in different clinical settings. ${ }^{9,18,19}$

This review aims to describe the current status of available PFT that employs laboratory methodologies and pointof-care testing (POCT) with the pertinent instrumentation for different clinical settings. Different methodologies are employed both in the diagnosis of inherited and acquired bleeding disorders and in the monitoring of residual platelet reactivity of patients on antiplatelet treatment.

\section{Platelet function methods}

In recent years, the assessment of platelet (dys)function has become increasingly necessary in a variety of clinical settings: 1) for the identification of patients with bleeding disorders; 2) for monitoring the response to antiplatelet treatment; 3 ) in the evaluation of perioperative hemostasis; and 4) in transfusion medicine. Because there are diverse employment fields in which platelet function is studied and the platelets present a plethora of functions, different methodologies have been developed. Indeed, the platelet methods are based on different operating principles, and few assays are able to investigate "all in one device" platelet activation pathways. The different modalities of devices to operate may be based on the assessment of platelet adhesion and aggregation, on the submission of platelets under special shear conditions, on the analysis of physical properties of clot, and on the measurement of platelet compounds. ${ }^{8,9}$ In addition to the wide set of assays and devices for studying platelet function, because platelets are cells that may be easily activated during the blood sampling, a number of preanalytical variables can produce platelet artifacts affecting the different platelet functions. Therefore, a high degree of experience and expertise is necessary to perform and interpret PFT. In this sense, this review attempts to make a comparison of the various platelet function methodologies on the basis of the same principle that both are laboratory tests or POCT. The different platelet function tests reported in this review are grouped by the various methodological 
principles in Table 1, and the pros and cons of some platelet tests are documented in Table 2.

\section{Bleeding time}

$\mathrm{BT}$ is the first test designed for evaluating in vivo primary hemostasis. ${ }^{10} \mathrm{BT}$ assesses the platelet ability to develop a hemostatic plug by recording the time that the platelets take to occlude an in vivo skin wound for stopping the hemorrhage. ${ }^{20}$ Although the technique is easy and quick to perform without any WB processing, it is influenced by different variables such as differences in skin thickness and temperature among patients and an incorrect management of the test procedure. Nevertheless, the use of available devices to standardize the test, a lack of accuracy, and unclear association with clinical patient state persist. No study has clearly established the ability of BT evaluation to predict the risk of bleeding in patients, and a study only reported that BT could predict clinical bleeding in patients with acute myocardial infarction undergoing thrombolytic therapy. ${ }^{21,22}$ Moreover, this test is not used routinely to monitor the effect of antiplatelet therapy. ${ }^{23}$ Nevertheless, BT is still regarded as a screening test to identify both congenital and acquired disorders of primary hemostasis in those laboratories that do not perform other platelet function tests.

\section{Tests based on platelet aggregation Light transmission platelet aggregometry on platelet-rich plasma}

LTA, designed by Born in the 1960s, is performed by using the PRP as milieu. ${ }^{12,24}$ It is still deemed the gold standard test for the

Table I Different methodologies for assessment of platelet function

\begin{tabular}{|c|c|c|c|}
\hline Method & Sample & Method application & Method principle \\
\hline Bleeding time & Native WB & Screening test (obsolete) & In vivo measurement of bleeding block \\
\hline \multicolumn{4}{|c|}{ Tests based on platelet aggregation } \\
\hline & Citrated PRP & Screening test for bleeding tendency & Photo-optical measurement of light \\
\hline aggregation (LTA) & & Diagnostic for platelet defects & transmission increase in relation \\
\hline & & Monitoring antiplatelet treatment effect & to agonist-induced platelet aggregation \\
\hline Impedance platelet aggregation & Citrated WB & Screening test for bleeding tendency & Measurement of electrical impedance \\
\hline & & Diagnostic for platelet defects & increase in relation to agonist-induced \\
\hline & & Monitoring antiplatelet treatment effect & platelet aggregation \\
\hline Lumiaggregometry & Citrated WB & Detection of storage/release disorders & $\begin{array}{l}\text { LTA or WB aggregometry combined } \\
\text { with luminescence }\end{array}$ \\
\hline Plateletworks & Citrated WB & $\begin{array}{l}\text { Monitoring of the platelet response } \\
\text { to antiplatelet agents }\end{array}$ & $\begin{array}{l}\text { Platelet counting pre- and postactivation } \\
\text { in whole blood }\end{array}$ \\
\hline \multicolumn{4}{|c|}{ Tests based on platelet adhesion under shear stress } \\
\hline PFA-I00; Innovance PFA-200 & Citrated WB & $\begin{array}{l}\text { Assessment of bleeding risk and drug effects } \\
\text { Searching severe platelet dysfunctions, } \\
\text { revealing of VWD }\end{array}$ & $\begin{array}{l}\text { Time evaluation of high shear WB flow } \\
\text { blocked by platelet plug into a hole } \\
\text { in activated surface }\end{array}$ \\
\hline $\begin{array}{l}\text { Impact; Cone and Plate(let) } \\
\text { Analyzer }\end{array}$ & Citrated WB & Screening of primary hemostasis & $\begin{array}{l}\text { Shear-induced platelet adhesion-aggregation } \\
\text { upon specific surface }\end{array}$ \\
\hline Global thrombosis test (GTT) & Native WB & $\begin{array}{l}\text { Evaluation of platelet function } \\
\text { and thrombolysis }\end{array}$ & $\begin{array}{l}\text { Measurement of time cessation of WB } \\
\text { flow by high shear-dependent platelet plug } \\
\text { formation }\end{array}$ \\
\hline \multicolumn{4}{|c|}{ Platelet function methods combined with viscoelastic test } \\
\hline TEG/platelet mapping system & Citrated WB & $\begin{array}{l}\text { Assessment of global hemostasis plus } \\
\text { monitoring antiplatelet treatments effect }\end{array}$ & $\begin{array}{l}\text { Evaluation of rate of clot formation } \\
\text { based on low shear-induced and agonist } \\
\text { addition }\end{array}$ \\
\hline ROTEM platelet & Citrated WB & $\begin{array}{l}\text { Assessment of global hemostasis plus } \\
\text { diagnostic of platelet defects plus } \\
\text { monitoring antiplatelet treatments effect }\end{array}$ & $\begin{array}{l}\text { Measurement of electrical impedance } \\
\text { increase in relation to agonist-induced } \\
\text { platelet aggregation }\end{array}$ \\
\hline \multicolumn{4}{|c|}{ Platelet analysis based on flow cytometry } \\
\hline Flow cytometry & $\begin{array}{l}\text { Citrated WB, } \\
\text { PRP, W-Plt }\end{array}$ & $\begin{array}{l}\text { Cell counting, detection platelet activation } \\
\text { by extent of expression of surface and/or } \\
\text { cytoplasmic biomarkers }\end{array}$ & $\begin{array}{l}\text { Engineering laser-based detection } \\
\text { of suspending fluorescent label platelets } \\
\text { in a flowing solution }\end{array}$ \\
\hline \multicolumn{4}{|c|}{ Evaluation of Thromboxane metabolites } \\
\hline $\begin{array}{l}\text { Radio- or enzyme-linked } \\
\text { immune assays }\end{array}$ & $\begin{array}{l}\text { Serum, urine, } \\
\text { citrated Pls }\end{array}$ & $\begin{array}{l}\text { Measurement of TxA2 metabolites } \\
\text { (and Beta-TG, PF4, soluble P-selectine) }{ }^{\mathrm{a}}\end{array}$ & Ligand-binding assays \\
\hline
\end{tabular}

Note: aNot planned in this review.

Abbreviations: Beta-TG, beta-thromboglobulin; Pls, plasma; PRP, platelet-rich-plasma; ROTEM, rotational thromboelastometry; TEG, thromboelastography; TxA2, thromboxane A2; WB, whole blood; W-Plt, washed platelets; VWD, Von Willebrand disease. 
Table 2 Pros and Cons of reviewed platelet function tests

\begin{tabular}{|c|c|c|}
\hline Method & Pro & Contra \\
\hline \multirow[t]{4}{*}{ Bleeding time } & In vivo test, quick & Invasive \\
\hline & No WB processing & Poorly standardized \\
\hline & & Dependent on many variables \\
\hline & & (skin thickness, and temperature operator's skills) \\
\hline Light transmission platelet & Historical gold standard & Manual sample processing \\
\hline \multirow[t]{4}{*}{ aggregation (LTA) } & Diagnostic method & Pre- and analytic variables \\
\hline & Flexible & High sample volume \\
\hline & Different platelet pathways investigated & Time-consuming \\
\hline & Sensitive to anti-plt therapy & \\
\hline \multirow[t]{6}{*}{ Impedance Platelet Aggregometry } & No sample processing & Limited HCT and platelet count range \\
\hline & Diagnostic method & \\
\hline & Flexible & \\
\hline & Different platelet pathways investigated & \\
\hline & Sensitive to anti-plt therapy & \\
\hline & Close to POCT (multiple system) & \\
\hline \multirow[t]{4}{*}{ VerifyNow system } & Waived POCT & Nonflexible \\
\hline & No WB processing & Very expensive \\
\hline & Easy, quick & Monitoring antiplatelet therapy \\
\hline & & Limited HCT and platelet count \\
\hline \multirow[t]{3}{*}{ Plateletworks } & POC system & Indirect assay \\
\hline & Minimal sample preparation & Required adjunctive platelet count \\
\hline & Easy, rapid screening test & Scarce data \\
\hline \multirow[t]{3}{*}{ PFA-100; Innovance PFA-200 } & In vitro standardized BT & Rigid closed system \\
\hline & Easy, quick POCT & Platelet count - HCT-dependent \\
\hline & Sensitive to severe platelet defects & Not sensitive to platelet secretion defects. \\
\hline \multirow[t]{4}{*}{ Impact Cone and Plate(let) Analyzer } & WB assay & Expensive \\
\hline & Global platelet method & Experienced staff \\
\hline & Small sample volume & Lack of clinical studies \\
\hline & & Not widely available \\
\hline \multirow[t]{3}{*}{ Global thrombosis test (GTT) } & WB assay & Lack of clinical studies \\
\hline & Global platelet method & Not widely available \\
\hline & Small sample volume & \\
\hline \multirow[t]{3}{*}{ TEG platelet mapping } & POCT & Measure clot properties \\
\hline & Global hemostasis test & More studies are needed \\
\hline & Reduces blood transfusions & \\
\hline \multirow[t]{6}{*}{ ROTEM platelet } & РОСТ & Limited HCT and platelet count range (for \\
\hline & Predicts bleeding & platelet system) \\
\hline & Reduces blood transfusions & Lack of clinical studies \\
\hline & Improves clinical outcome & \\
\hline & Global hemostasis test & \\
\hline & WB platelet aggregometry & \\
\hline
\end{tabular}

Abbreviations: BT, bleeding time; HCT, hematocrit; plt, platelet; POC, point-of-care; POCT, point-of-care testing; ROTEM, rotational thromboelastometry; TEG, thromboelastography; WB, whole blood.

assessment of the various platelet functions. Indeed, by adding a wide panel of agonists to PRP, a considerable amount of data are obtained about the various pathways of platelet activation. ${ }^{13}$

This test assesses in vitro the platelet-to-platelet clump formation in a glycoprotein (GP) IIb/IIIa-dependent manner, ie, the aggregation, the most important function of platelets. The assay is based on the measurement of the increase in light transmission through the optically dense sample of PRP after the addition of the exogenous platelet agonist. During the assay, the PRP after the addition of agonist becomes clearer because of the precipitation of platelet aggregates.
This determines an increase in light transmission through the plasma sample. The device records the rate and maximal percentage of this increase from $0 \%$ (maximal optical density of PRP) to $100 \%$ (no optical density of autologous platelet-poor plasma) by a photometer. This signal is converted automatically in a graphic curve that parallels the increase in light transmission during the platelet aggregation (Figure 1). The available aggregometers are easy-to-use devices equipped with automatic setting (100\% and $0 \%)$, software for storing results and disposable cuvettes with a stirring bar. The slope of the curve, the maximal extent of aggregation (\%), and the 

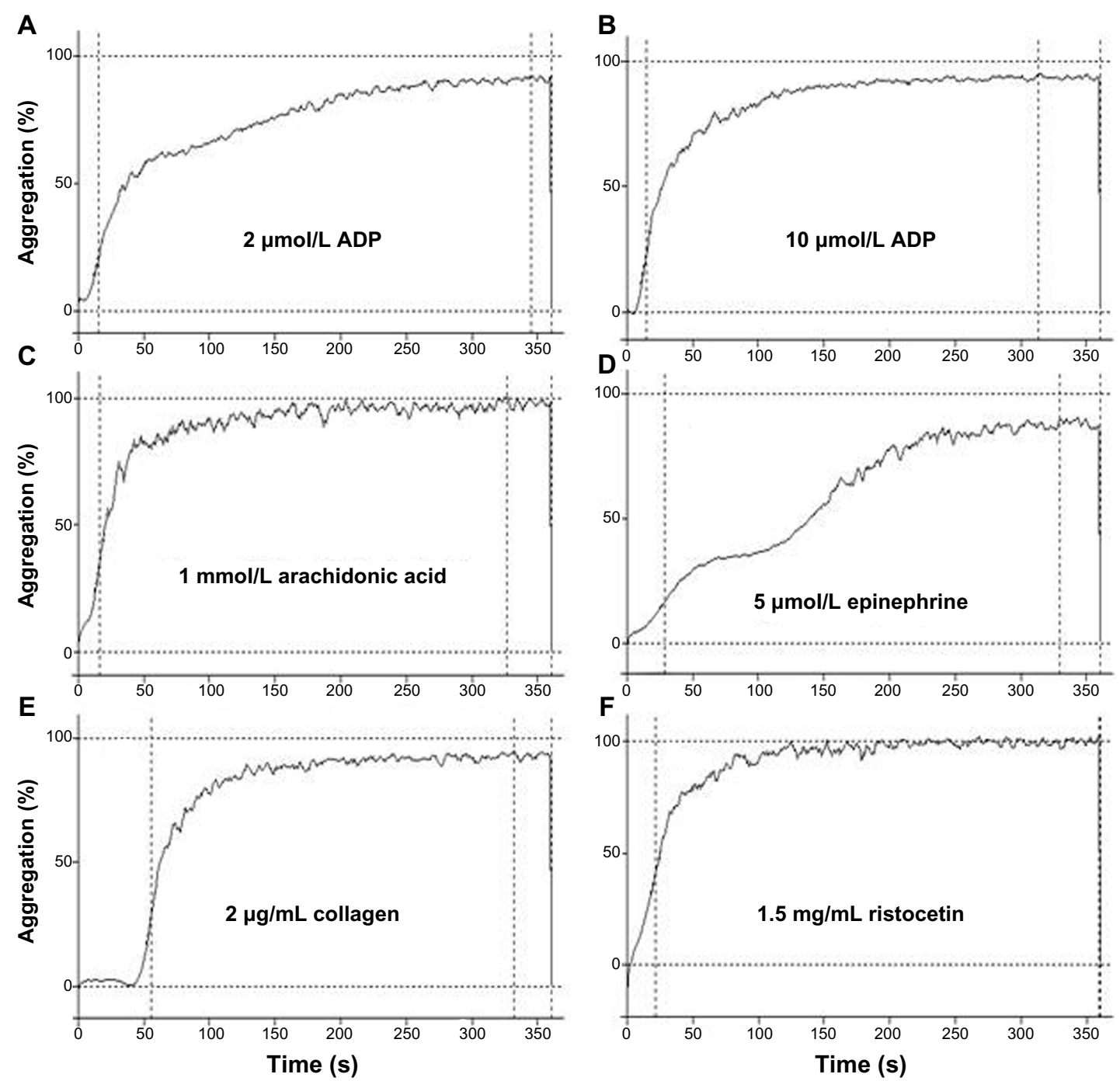

Figure I Light transmission platelet aggregation tracings from a healthy subject in response to different agonists.

Note: (A-F) Final concentrations are reported.

Abbreviation: ADP, adenosine-diphosphate.

latency time (lag phase) are the parameters automatically measured, and the shape change and primary and secondary aggregation may be seen graphically. To the PRP sample, different agonists are added to stimulate different platelet activation pathways, obtaining information about the several features of platelet function.

Born's platelet aggregometry is the most widely employed methodology for detecting platelet function disorders and monitoring antiplatelet therapies. Actually, it is deemed the first step in the flowchart for the study of hemorrhagic patients with inherited or acquired platelet dysfunctions. ${ }^{25-29}$ At the first sign of congenital/acquired bleeding disorders, in addition to the most commonly used agonists ADP, AA, collagen, and epinephrine, other agonists should be employed: thrombin receptor activating peptide (TRAP), Thromboxane A2 (TXA2) mimetic U46619, calcium ionophore A23187. The antibiotic ristocetin is another agent used as agonist in the assessment of platelet function. It facilitates the binding of Von Willebrand Factor (VWF) to the glycoprotein Ib/IX/V complex. Different concentrations of ristocetin are used: this way of dose-response allows one to investigate both increased and decreased sensitivity to ristocetin. For a normal result, both functional VWF and normal glycoprotein $\mathrm{Ib} / \mathrm{IX} / \mathrm{V}$ complex must be present. Hence, ristocetin-induced platelet aggregation is considered a test that can detect both VW disease and platelet dysfunctions such as Bernard-Soulier syndrome..$^{29}$

Monitoring antiplatelet therapies (eg, aspirin and thienopyridine) by using LTA has permitted the prediction of major adverse cardiovascular events (MACE) in cardiovascular patients at high risk. The rate of residual platelet reactivity defined by ADP-, AA-LTA, or both has been associated with the development 
of ischemic events both in acute coronary syndrome (ACS) patients and in those with stable coronary artery disease. Not only the previous evaluation of degree of platelet inhibition in stable cardiovascular artery disease (CAD) patients, but also the laboratory and clinical research of a cut-off value for ADP and/or AA-induced platelet aggregation have been instrumental in identifying those ACS patients who are nonresponders to antiplatelet agents and are at high risk of MACE. ${ }^{30-33}$

Although LTA is accepted as the most important and complete assay that clinical laboratories can perform to diagnose platelet function disorders, this assay presents some peculiar problems. Indeed, the technique may be affected by different preanalytical conditions (ie, type of anticoagulant, lipid plasma, hemolysis, or low platelet count), and by different procedural conditions (ie, PRP preparation, use of different concentrations of agonists), and the laboratory staff should have a high degree of skill, experience, and expertise in performing and interpreting platelet function. Hence, this method is constantly verified by an ongoing standardization process, ${ }^{25,34,35}$ and recent specific guidelines for LTA aimed at stabilizing/normalizing the correct procedure have been published. ${ }^{36-39}$

Finally, LTA test is the first diagnostic step in the evaluation of platelet disorders as reported by different studies..$^{25,28}$ Because platelet dysfunction may be caused by a plethora of factors, for achieving a diagnostic hypothesis, the results obtained by LTA should be confirmed by further specific tests. By using flow cytometry analysis for the identification of expression of specific platelet components and lumiaggregometry for the identification of impaired platelet secretion or the Platelet Function Analyzer-100 (PFA-100) system, performed as a second diagnostic, LTA as a first-step diagnostic tool can be specifically confirmed. ${ }^{28}$

\section{Impedance whole blood aggregometry}

Impedance whole blood aggregometry (WBA) allows one to assess platelet function by using the anticoagulated WB as milieu without any sample processing. ${ }^{40} \mathrm{It}$ is based on the principle that activated platelets stick via their surface receptors to artificial surfaces of two electrodes within the WB sample positioned at a determined distance between them. Platelet aggregation is assessed by detecting the increase in electrical impedance generated by the aggregation of other platelets upon those fixed to the electrodes. Hence, by diminishing the current intensity, the electrical impedance increases. The degree of the increase in impedance is recorded in Ohms. ${ }^{14}$

By the utilization of WB aggregometry, platelet function is assessed under more physiological conditions given that the contributions of other blood elements also may affect platelet function. Another key aspect is that WB aggregometry takes place on surfaces, which enables this assay to be more adherent to the actual capacity of platelets to adhere and aggregate upon a solid phase. Moreover, WBA presents two important advantages: 1) use of a small quantity of WB in which all subpopulations of platelets are present; 2) no manipulation of the sample without activation of platelets, resulting in a rapid analysis of platelet function.

Now, the Multiple Electrode Aggregometry (MEA) is a new methodology by which the WB platelet aggregation can be assessed by using a new pertinent device that allows one to consider this assay as a POCT. ${ }^{41}$ Recently, this new aggregometer (Multiple Platelet Function Analyzer Dynabyte - Roche Diagnostics, Mannheim, Germany) has become available across the world. The device presents particular features that make it a valid tool for rapid and complete platelet function evaluation. It is a five-channel computerized instrument equipped with disposable cuvettes ready to use with two independent sensor units and an automated pipetting. The reagents - agonists and diluents - are ready to use. The platelet aggregation is simultaneously measured in duplicate by using each sensor unit separately and calculated automatically as area under curve (AUC). With these important advantages MEA has acquired a high clinical value like that of LTA, and the use of different agonists similar to those used for LTA has made it suitable for the diagnosis of bleeding diathesis and for monitoring antiplatelet therapies, defining cut-off values to discriminate cardiovascular patients with high on-treatment platelet reactivity. ${ }^{42-49}$ MEA has been used to study the occurrence of VWD in patients with severe aortic stenosis and, on the other hand, the high thrombotic risk due to heparin-induced thrombocytopenia (HIT). ${ }^{50,51}$

In addition, MEA has not only been able to identify cardiovascular patients not responding to antiplatelet agents and at risk of MACE, but has been considered a skill assay to distinguish those patients with a high inhibition of platelet function and at risk of bleeding. ${ }^{52-54}$ Ranucci et al ${ }^{55}$ reported that investigating platelet function by using MEA before cardiac surgery has made it possible to identify the hyperresponder patients at risk of postoperative bleeding. Recently, it was reported that low extent of TRAP-induced platelet aggregation by MEA was defined as a factor independently associated with intramyocardial hemorrhage in patients with myocardial infarction. ${ }^{56}$ Actually, multiple evidence reveals that MEA might be able to identify pre-/postoperatively those patients at risk of blood loss. Hence, this platelet function test has been proposed as a rapid and useful tool for the management of postoperative severe bleeding..$^{56-58}$ 
MEA, overcoming the traps that LTA presents, may allow the rapid assessment of the platelet function without the requirement of a specialized laboratory. This POC system requires minimal technical knowledge and training to perform accurately, the working steps are automatically accomplished and easily controlled, and only interpretation data and judgment are required. Probably, in the future this test will be able to have a similar clinical value as of LTA with the advantage of its use in general laboratories.

\section{Lumiaggregometry}

Lumiaggregometry allows simultaneous measurement of the release of adenine nucleotides from platelet granules and platelet aggregation. ${ }^{16,59-61}$ The method is based on the evaluation of adenosine triphosphate (ATP) released from activated platelets by different agonists by using a luminescence technique in PRP, washed platelets (WP), or WB. ${ }^{62-65}$ The assay is based on the conversion of ADP, released from the platelet dense granules, to ATP that reacts with the luciferinluciferase reagent. The light emitted, proportional to the ATP concentration, is quantified by the lumi-aggregometer. This technique is used for evaluating specific deficiencies in the number and content of dense granules: the so-called storage pool defects or specific defects in degranulation. ${ }^{8,9,62-65}$ As with LTA, this analysis might be used as a first screening test of patients with clinical suspicion of platelet function defects such as abnormalities of platelet granule secretion and/or content, plasma membrane receptor defects, and to evaluate platelet functions during thrombocytopenia. ${ }^{28,66,67}$

\section{VerifyNow system}

The VerifyNow system (ITC, Edison, NJ, USA) is a platelet function-waived POCT consisting of a device that assesses in WB platelet aggregation by a turbidimetric-based optical detection and using a system cartridge containing fibrinogencoated beads and platelet agonists. ${ }^{68}$ The method is based on the capacity of activated platelets to bind to fibrinogen: platelets aggregate upon the fibrinogen-coated beads within the assay cartridge in proportion to the number of activated GPIIb/IIIa receptors. The crossing WB optical signal increases as the activated platelets aggregate to the fibrinogen attached to the spheres. The use of this closed system requires no blood manipulation and instrument handling: actually, the methodology is very waived and it is largely employed to monitor antiplatelet therapies in the emergency cardiac operating room without the help of a specialized laboratory. ${ }^{54}$ Formerly, the method (called Ultegra) was used to verify the inhibitory effect of platelet GPIIb/IIIa antagonists (abciximab or eptifibatide) in cardiovascular patients undergoing percutaneous coronary intervention (PCI): in this assay (VerifyNow IIb/IIIa Test), the thrombin receptor activating peptide (iso-TRAP) is used as agonist to maximally stimulate platelet aggregation. ${ }^{69}$ The device reports patient results as Platelet Aggregation Units (PAU) calculated as rate and degree of aggregation. Now, two more assays each sensitive to targeted drugs are available: Aspirin Test with AA as agonist (sensitive to aspirin therapy), whose results are expressed as Aspirin Reaction Units (ARU); and PRUTest (sensitive to thienopyridine treatment), whose results are expressed as P2Y12 Reaction Units (PRU), by using $\mathrm{ADP}$ as agonist and $\mathrm{PGE}_{1}$ as suppressor of intracellular free calcium levels for diminishing the nonspecific influence of the ADP-binding to P2Y1 receptors. The VerifyNow system showed a moderate agreement with other platelet function tests. The assessment of the sensitivity and specificity of the method and the definition of a cut-off value for classifying patients at high risk of MACE and not responsive to acetylsalicylic acid (ASA) or thienopyridines have been debated and different laboratories and clinical studies have reported the clinical value of this system. ${ }^{70-77}$ Recently, in surgical settings, the use of the VerifyNow system in patients on antiplatelet agents has been expanding for attempting to predict postoperative hemorrhage..$^{78,79}$

\section{Plateletworks system}

This system is a WB POC assay based on the measurement of platelet count before and after aggregation. This system consists of the Plateletworks aggregation kit formed by EDTA tubes and citrate tubes implemented with agonists (ADP or AA) and the Ichor blood counter (Helena Laboratories, Beaumont, TX, USA). ${ }^{80}$ The Plateletworks method matches the platelet count assessed in the control sample (EDTA tube) with those obtained after aggregation in citrate blood with ADP or AA (citrate tube plus agonist). Since platelets aggregate, the fall in their count measured in citrate tubes is the extent of activated platelets that have aggregated themselves. This rapid test does not need any manipulation of blood sample, and results are ready in minutes. A disadvantage of the test is that it should be performed within a few minutes of blood sampling. The need for this strict time interval has relegated this analysis to restricted operating areas such as cardiac surgery and cardiac operating room. Relationships between Plateletworks and LTA, VerifyNow system and Thromboelastography have been reported as validation test for monitoring antiplatelet therapy ${ }^{81-83}$ In acute care condition, Plateletworks shows the clinical value of giving information about both platelet count and function. ${ }^{84,85}$ 
Nevertheless, it is still under consideration and has not been reported to predict clinical outcomes.

\section{Tests based on platelet adhesion under shear stress}

\section{The Platelet Function Analyzer -} PFA-100/Innovance PFA-200

The Platelet Function Analyzer - PFA-100/Innovance PFA-200 is a PFT that uses a device called the PFA-100 or the new available and updated Innovance PFA-200 (Siemens, Munich, Germany). At the beginning, PFA-100 has been considered as the standardization of $\mathrm{BT}^{86,87}$ The method is based on the property of platelets to adhere upon shear stress conditions and aggregate in consequence of agonist presence in the system. This methodology is considered a POCT that assesses platelet function in WB using appropriate cartridges in which primary hemostasis is simulated. ${ }^{88-90}$ Two different test-cartridges containing either collagen (C) plus ADP - CADP cartridge or collagen plus epinephrine (EPI) - CEPI cartridge - are available. Within the cartridge, the citrated WB is drawn at a high shear stress rate through a capillary that has at its end a collagen-coated membrane, in which a defined microscopic aperture $(147 \mu \mathrm{m})$ is present, filled with either ADP or EPI. A platelet clot, which fills the hole, occurs because of shear stress and agonists. The time taken by platelets to occlude the orifice and to block the WB flow is defined as closure time (CT), a measure of overall platelet-related hemostasis. The CT is as much prolonged as the platelets are able to act.

The use of two different assay cartridge allows to differentiate platelet defects due to intrinsic or platelet defects (prolonged times of CADP cartridge alone or plus CEPI cartridge) such as VW defects or Bernard-Soulier syndrome or Glanzmann's thromboasthenia from those due to antiplatelet therapy with ASA (prolonged time of CEPI cartridge). ${ }^{70,90-93}$ In comparison with BT test, this assay has been shown to be more sensitive, ${ }^{70,89}$ especially for diagnosis of VWD and platelet function defects. ${ }^{91}$ Recently, a third diagnostic, the new Innovance cartridge, sensitive to the thienopyridine therapy, has become available, but information on its clinical value is poor and limited. ${ }^{94}$

The PFA-100 is sensitive to many variables that influence platelet function - prolonging the $\mathrm{CT}$ - as well as low platelet count and hematocrit, conditions associated with thrombocytopathies. Thus, the clinicians should take these limitations into account. On the other hand, factors such as high levels of VWF, fibrinogen, or erythrocytes have been reported to shorten CEPI CT. ${ }^{95,96}$ In addition, a short CEPI CT could reveal high residual platelet reactivity despite aspirin therapy, thereby predicting the risk of thromboembolic events. ${ }^{97,98}$ Indeed it has been demonstrated in ACS patients on ASA treatment that a high concordance exists between LTA and the PFA-100 CEPI test, giving significant negative predictive value to the PFA system. ${ }^{65}$ In addition, PFA CEPI CT shortened results were demonstrated to be a significant and independent predictor of MACEs in patients with acute myocardial infarct (AMI) undergoing primary PCI. ${ }^{99-101}$ In patients undergoing different kinds of elective surgeries, the assessment of platelet dysfunction with PFA-100 may provide useful information for postoperative blood transfusion management. ${ }^{102,103}$ Especially in cardiac surgery, PFA methodology showed a high predictive value of platelet function for management of intra- and postoperative blood loss. ${ }^{104-107}$ In patients with biventricular assist device implantation, on treatment with clopidogrel, the use of CADP diagnostics for monitoring the degree of platelet inhibition allowed them to undergo transplantation without major blood loss. ${ }^{108}$ In addition, prolonged CADP CTs were found be independent risk factors for postpartum hemorrhage (PPH) severity and were significantly related to menorrhagia. ${ }^{109,110}$ Presurgical prolonged CTs corrected with 1-deamino-8-D-arginine vasopressin (DDAVP), ie, desmopressin treatment, made it possible to keep unchanged the quantity of postoperative blood transfusions with respect to those provided to patients with normal presurgical CTs. ${ }^{102}$

It has been recommended that the PFA system be employed as a screening tool integrated into a panel of existing tests. ${ }^{28,38}$ This assay is characterized by a high negative predictive value: when a normal CT result is found in a suspected platelet disease, further PFT should not be performed. ${ }^{5}$

\section{IMPACT: Cone and Plate(Let) Analyzer}

IMPACT: Cone and Plate(Let) Analyzer (Image Analysis Monitoring Platelet Adhesion Cone and Plate Technology) (CPA) (DiaMed, Cressier, Switzerland) is a novel and innovative POC test that fully assesses platelet function by using an automatic and computerized system that evaluates in vitro primary hemostasis. ${ }^{111}$ The test is based on the in vitro activation and adhesion of platelets that lie all over a standardized plate covered by a substrate of polystyrene. The shear stress force is impressed to platelets by the spinning of a cone on the plate. Citrated WB is used in the system that is formed by the reaction device - cone and plate - an automatic staining device and image analysis software. After automated staining, the percentage of the well surface covered by platelet aggregates - representing platelet adhesion - and the average size of the aggregates (per $\mu \mathrm{m}^{2}$ ) - representing platelet aggregation - are measured. 
This system is highly dependent on plasma. This instrument methodology could be a consistent system for the diagnosis of platelet defects. Moreover, the addition of the agonists AA and ADP in the system has made it possible to monitor and evaluate the efficacy of dual antiplatelet therapy. ${ }^{112,113}$ However, additional studies should be undertaken to assess its possible role in the diagnosis of inherited or acquired platelet dysfunctions.

\section{The global thrombosis test}

The global thrombosis test (GTT) (Montrose Diagnostics Ltd, London, UK) is a recent test that assesses platelet function in a manner close to physiological conditions because this technique is performed by using native nonanticoagulated WB, without adding agonists. ${ }^{114-116}$ The principle on which it is based is platelet activation due to high shear stress, opportunely provoked, similar to that in coronary artery stenosis. In this new system, the WB flows into a plastic tube that holds a conical part in which two ceramic balls are placed. The complete occlusion of the tube lumen due to the presence of the spheres is prevented by the flat segment created along the inner wall of the tube. WB flows under the force of gravity through the four narrow gaps of the first ball where high shear stress activates platelets. In the space underlying the first ball, low shear and turbulent flow support platelet aggregation. The platelet plug occludes the gaps at the level with second ball at the end tube and the WB exits always more slowly in the form of drops. In the first phase, the occlusion of the tube system, expressed as occlusion time (OT) in seconds, occurs. The time of interval $(d)$ between two consecutive drops is recorded until an arbitrary endpoint ( $d \geq 15$ seconds) is reached. In the second phase, the blood flow resumes at the end of the tube owing to spontaneous lysis of occlusion expressed as lysis time (LT) in seconds. This rapid POC test provides results on the patient's thrombotic status, and it is thus employed in acute and critical care settings, as well as in more general screening. ${ }^{116-118}$ The evaluation of GTT results in association with clinical outcomes is still in progress. However, because GTT presents a double clinical value, this test might play a role in the future for the assessment of platelet function. ${ }^{15,119}$

\section{Platelet function methods in conjunction with viscoelastic methodologies \\ TEG platelet mapping system and ROTEM platelet test}

Thromboelastography and thromboelastometry are methodologies employed for the global assessment of the hemostatic process. These assays investigate the entire development of clot formation and are based on the analysis of $\mathrm{WB}$ modifications in viscoelastic forces during the clotting formation. Indeed, the potential of this methodology is related to assessing the extent of platelet count and function, clotting, and fibrinolytic activation. ${ }^{120}$ In these tests, platelets play all their functional roles in hemostasis: thrombin generation, clot formation, clot retraction, and lysis.

At present, three principal systems are available: Thromboelastography, performed on "old" renewed devices (TEG; Haemoscope, IL, USA), Thromboelastometry, formerly called Rotational Thromboelastography, performed on a new device (ROTEM; TEM Int, Munich, Germany), and Sonoclot analysis performed on a new device (Sonoclot Signature; Sienco, CO, USA). The principle underlying the method for TEG and ROTEM consists in a rotating system inclusive of a pin suspended by a torsion wire in a cup. In the WB sample, owing to the addition of reagents and the shear stress of the rotating system, the forming clot entraps the pin promoting a motion that increases as the clot strengthens and decreases as the clot lyses. In the Sonoclot device in the cup, the pin is moved up and down at an ultrasonic rate. ${ }^{121}$

The in vitro addition of specific reagents and activator to WB provokes the hemostatic activation followed by modifications in hematic viscoelastic forces: the entire process is instantly recorded during all clotting formation and also visualized in a typical curve. Different tests are available depending on the reagent used: tissue factor for extrinsic pathway, different activators (glass, silica, kaolin, ellagic acid) for intrinsic pathway. Those additional compounds are used for revealing particular aspects of hemostasis: heparinase for evaluating the degree of anticoagulation of heparin, aprotinine for evaluating the activation of fibrinolysis, and antiplatelet agents (cathepsin G or GPIIb/IIIa antagonists) for eliminating the contribution of platelets to clotting formation. For each test, different parameters, indicating the different steps of hemostasis, are shown after the recognition and computation by the integrated software detection: $\mathrm{K}$ index (TEG) and Clot Formation Time (CFT, ROTEM) recognizes platelet function, Angle alpha (for both) indicates the rate of fibrin-formation, Maximal Amplitude (MA, TEG) and Maximum Clot Firmness (MCF, ROTEM) indexes show the platelet contribution to clot formation. In addition, by the selective activation of extrinsic pathway without and with antiplatelet agents (ie, clotting by fibrinogen alone), it is possible to evaluate the extent of platelet contribution to the clot formation. Because all this instrumentation promptly delivers a graphic representation of clot formation and lysis, they are now used as POC devices in different clinical settings such as 
cardiac surgery, liver transplantation, obstetrical emergency, and trauma center. ${ }^{122-135}$ To date, the clinical value of this technology has consisted in offering a predictive evaluation of the risk of increased postoperative bleeding. For surgical and emergency settings, different studies have documented flow charts in which are reported when to use these systems and how to interpret their results in patients at risk of bleeding, such as those on antiplatelet treatment. Actually, it has now been identified how the use of the different parameters provided by these tests may be predictors of both postoperative bleeding and blood product use. ${ }^{136-138}$

Currently, new applications for the study of platelet function are available. The TEG platelet mapping system is a modification of the original TEG and has been developed for monitoring antiplatelet therapy. ${ }^{139-142}$ First, a kaolin-activated test is performed to evaluate the maximal hemostatic activity. Second, a test in the presence of reptilase and Factor XIIIa (activator F) is used to produce a cross-linked fibrin clot. The addition of ADP or AA stimulates differentially the role of platelet ADP or TXA2 receptors in clot formation. The effect of therapy with aspirin (AA addition) or thienopyridines (ADP addition) is evaluated by comparing the TEG kaolin-activated test curve with the AA or ADPstimulated TEG curve. The method has been shown to be reliable with low analytical variation. ${ }^{143,144}$ However, further large prospective studies should be performed in order to define the possible role of these devices in monitoring antiplatelet therapy.

On the other hand, the ROTEM platelet system is a new module that could be added to the ROTEM. A WB aggregometer as an integrated module has been added to the ROTEM system. This allows a deeper analysis of the primary hemostasis of the patient along with that of coagulation. The measurement is based on true impedance aggregometry (such as the MEA system), which allows the measurement of platelet aggregation in WB samples. The software for the analysis data is the same as of the ROTEM system. In this manner, the platelet function analysis is visualized together with the thromboelastometric measurements, altogether on the same screen; in fact, the two different assays (both thromboelastometry and platelet aggregometry) can be run together in the same time on the same system. Some characteristics of the ROTEM platelet are similar to those of MEA, such as single-use cuvettes, time of test, measured parameters, and agonists used. Because the availability of this assay is very recent - it goes back to a few months ago - only a few data are currently available about its laboratory and clinical value. ${ }^{145}$

\section{Platelet analysis based on flow cytometry}

Flow cytometry (FC) is a technique of rapidly measuring specific characteristics of many different cells such as platelets, measuring the cell size, and granularity. FC analysis of platelets may offer information on their functional status in vivo, and this technique encompasses multiple assays for several purposes such as the assessment of the activation state (platelet membrane-associated IgG), evaluation of thrombopoiesis, diagnosis of specific disorders, and antiplatelet agent monitoring. ${ }^{146-148}$

This analysis is based on the optical and fluorescence evaluation of physical - such as size and internal complexity and antigenic properties of platelets, ie, determination of surface receptors including conformational changes related to the receptor activation, platelet granule secretion, presence of platelet aggregates, and leukocyte-platelet aggregates. ${ }^{149}$ It consists of the measurement of antibodies conjugated to fluorescent dyes that may bind specific proteins on cell membranes or inside cells, revealing their presence. A light source, crossing labeled platelets, excites to a higher energy state the fluorescent molecules of dyes. When the fluorochromes return to a resting state, they emit light energy at different wavelengths. The use of multiple fluorochromes with similar excitation wavelengths, but different emission wavelengths (or "colors"), allows several cell properties to be measured simultaneously. Different fluorochromes such as fluorescein isothiocyanate (FITC) or phycoerythrin (PE) can be used, but also a specie-specific secondary antibody coupled to a fluorochrome can be employed to recognize a primary antibody linked to surface antigens. ${ }^{15}$ In the WB, the use of a double labeling binding allows the identification of platelets, platelet microparticles, or mixed cell aggregates. ${ }^{150-152}$ The results of FC are represented in the form of histograms with mean fluorescence intensity (MFI) plotted against cell number.

A plethora of platelet defects and features can be investigated by FC. Indeed, it can be a useful tool for the diagnosis of inherited (ie, Bernard-Soulier syndrome, Glanzmann's thrombasthenia) or acquired platelet dysfunctions (ie, HIT) and storage pool disease. As this analysis is able to assess platelet function defects in patients with very low platelet count, it is considered the test of choice to define the presence of thrombocytopathy in a thrombocytopenic patient. ${ }^{9}$ In this regard, an FC for the diagnosis of thrombocytopenic disorders has been developed to measure reticulated platelets. ${ }^{153}$ In addition, FC allows one to recognize the procoagulant capacity and activation state of platelets (eg, in the setting of acute coronary syndromes or cardiopulmonary bypass), 
by highlighting the expression of phosphatidylserine on activated platelet membranes using labeled annexin V. ${ }^{154}$

Different steps in intracellular signal transduction can be investigated by FC. Indeed, the intracellular quantification of Vasodilator Stimulated Phosphoprotein (VASP) phosphorylation by $\mathrm{FC}$ is the most used method for monitoring the efficacy of antiplatelet drugs. ${ }^{155,156}$ Finally, FC is used to evaluate the state of stored platelets in blood banks. For example, it is possible to assess the platelet activation state and identify leukocyte contamination of platelet concentrates for the evaluation of the efficacy of platelet transfusion. ${ }^{157-159}$

FC has many advantages, such as the use of small volumes of blood samples and the analysis of platelets in physiological milieu (WB). On the other hand, FC analysis is an expensive test, requiring specialized operators and devices, and the preanalytical phase can be affected by the delicate preparation prone to artifact unless carefully prepared..$^{8,9}$

\section{Evaluation of Thromboxane metabolites}

In physiological conditions, when platelets are stimulated by agonists, TXA2 is rapidly synthesized and released from platelets at the site of vascular injury. TXA2 amplifies the platelet activation, recruits additional platelets to the site of clot formation, and induces vasoconstriction, accelerating the hemostasis process. ${ }^{160} \mathrm{TXA} 2$ is the major product of the platelet metabolism of AA. AA, released from platelet membrane phospholipids via phospholipase A2 (PLA2), is converted in the endoperoxides, prostaglandin G2 (PGG2) and PGH2, via cyclooxygenase-1 (COX-1) and finally transformed into TXA2 by thromboxane synthase. TXA2 is rapidly transformed by hydrolysis into TXB2, a biologically inactive and stable product. ${ }^{160,161}$ TXB2 is excreted unchanged in urine in a small percentage being prevalently transformed into two major metabolites: 2,3-dinor-TXB2 and in 11-dehydro-TXB2 by $\beta$-oxidation and dehydration, respectively. These metabolites circulate in the plasma at low concentrations and are excreted in urine, and it has been established that 11-dehydroTXB2 is more abundant in urine than 2,3-dinor-TXB2. ${ }^{162,163}$ In inflammatory conditions, TXA2 can be produced by other biochemical pathways independently from platelets and extraplatelet sources of TXA2 can become relevant. ${ }^{164}$ Conversely, ASA interfering with COX-1 activity causes a decrease in the concentration of serum TXB2 and urinary 11-dehydro-TXB2. ${ }^{165,166}$

The measurement of TXA 2 metabolites allows evaluation of the activation state of platelets. ${ }^{89}$ Serum and urine TXB2 metabolites concentrations are related to the entity of TXA2 biosynthesis, and their dosage may be useful to assess platelet function in different diseases, to detect defects of thromboxane production, and to monitor aspirin therapy. ${ }^{8,9,167,168}$ Different ligand-binding assays based on the binding of the analyte to specific receptors by using different detection methods can be used to assess serum TXB2 and urinary 11-dehydro-TXB2 concentration, such as: 1) the "old" radioimmunoassays (RIA) or immunoradiometric assays (IRMA) that are now outdates; ${ }^{169-171} 2$ ) enzyme-linked immunoassays (ELISA) that are now the most commonly utilized assays. ${ }^{172,173}$

\section{Future perspective}

Different methodologies for the assessment of platelet (dys) function in order to screen different idiopathic or acquired pathological conditions - hemorrhagic and/or prothrombotic status - are currently available. At present, platelet tests are mostly used, thanks to the work put into the standardization of these tests, in the drawing up flowchart and to the introduction of primary hemostasis POCT. These available tests allow either the study of global platelet function or the evaluation of particular aspects of platelet activation. Primary hemostasis POC tests simultaneously may assess in vitro platelet adhesion and aggregation; platelet aggregation analysis is inclusive of platelet secretion and aggregation phenomena. In particular, in WB platelet aggregation, the role of other blood cells is considered; viscoelastic methods analyzing global hemostasis are able to individuate platelet dysfunction (Tables 1 and 2). Despite this versatility and their important clinical value, platelet assays pertaining to the same category (eg, those based on platelet aggregometry) are again affected by a wide range of methodological aspects. The numerous conditions involved in them cause an interlaboratory variability of results and can delay a clear standardized procedure. This major gap is partly overcome by the introduction of platelet function POCT, which presents a basilar standardized procedure. In light of this, a new platelet adhesion test using microfluidic devices, for example, a biochip containing several different adhesions, is under evaluation. ${ }^{174,175}$ Now, platelet spreading tests, using fluorescence microscopy or scanning electron microscopy, are frequently employed. ${ }^{176}$ On activation, platelets are able to release or express several compounds such as ATP, ADP, 5-HT, CXCL12, CD34, P-selectine, or thromboxanes, which may be assessed by using different methodologies such as immunological assay, High-performance liquid chromatography, fluorescence microscopy, or flow cytometry. ${ }^{28,177,178}$ The major drawback of the application of these assays in clinical practice is the scarcity and high variability of clinical and laboratory data and the absence of clear indications or guidelines for the correct use of such tests. Either for the 
study of global or single step of platelet function or for the definition of the clinical value of new platelet biomarkers, new or renewed platelet assays with high sensitivity and specificity are considered necessary, especially for routine laboratory analysis. In the future, it is desirable that specific, standardized, more rapid and easy tests - whose clinical value has been well defined - are available.

\section{Conclusion}

To date, the effort of translating the different PFTs as diagnostic tools for evaluating bleeding disorders and monitoring antiplatelet therapies is in progress. Actually, the available platelet function POCT is making possible the institution of platelet tests in laboratories and intensive care units, allowing their use in different clinical settings such as inherited bleeding disorders, cardiovascular intensive care, trauma coagulopathy, liver transplantation, and obstetric care for the prediction of bleeding. Similarly, the use of these POC tests could be extended not only at the bedside in critical areas outside of the specialized laboratory, but also in centralized and satellite laboratories. Indeed, the upgrading of the WB test, such as MEA, or platelet mapping or the new ROTEM platelet device, may guide clinicians in making the correct diagnosis of bleeding risk or in properly tailoring the antiplatelet therapy directly in pre-/postoperative care.

Nevertheless, for the amelioration of the ongoing standardization of LTA, new procedures were reported in 2010, 2011, and 2013. ${ }^{37-39}$ For this, PRP or WB platelet aggregometry by using new systems might be realized into routine laboratories. Because the availability of platelet tests is an important improvement, the drafting of validation procedures and the study of reliability and quality control testing of PFT are becoming an increasingly important issue.

In conclusion, the new POCTs available may be considered useful supplements to the existing well-known platelet function tests, but further prospective studies are necessary to define the applications of these tests. In the future, the improvements in the study of platelet genome and proteome may encompass knowledge of platelet function testing with a noteworthy impact on the diagnosis and management of patients affected by hemorrhagic or thrombotic defects.

\section{Author contributions}

Paniccia $\mathrm{R}$ conceived and designed the review, prepared the manuscript, and surveyed the literature; Priora R contributed to the literature review and preparation of the manuscript; Alessandrello Liotta A contributed to the preparation of the manuscript; and Abbate $\mathrm{R}$ approved the version to be published. All authors contributed toward data analysis, drafting and revising the paper and agree to be accountable for all aspects of the work.

\section{Disclosure}

The authors report no conflicts of interest in this work.

\section{References}

1. George JN. Platelets. Lancet. 2000;355:1531-1539.

2. Katz JN, Kolappa KP, Becker RC. Beyond thrombosis: the versatile platelet in critical illness. Chest. 2011;139:658-668.

3. Caudrillier A, Kessenbrock K, Gilliss BM, et al. Platelets induce neutrophil extracellular traps in transfusion-related acute lung injury. J Clin Invest. 2012;122:2661-2671.

4. Badimon L, Vilahur G. Thrombosis formation on atherosclerotic lesions and plaque rupture. J Intern Med. 2014;276(6):618-632. doi: 10.1111/ joim.12296.

5. Harrison P. Assessment of platelet function in the laboratory. Hamostaseologie. 2009;29:25-31.

6. Michelson AD. How platelets work: platelet function and dysfunction. J Thromb Thrombolysis. 2003;16:7-12.

7. Ruggeri ZM. Platelets in atherothrombosis. Nat Med. 2002;8: 1227-1234.

8. Pakala R, Waksman R. Currently available methods for platelet function analysis: advantages and disadvantages. Cardiovasc Revasc Med. 2011;12:312-322.

9. Kehrel BE, Brodde MF. State of the art in platelet function testing. Transfus Med Hemother. 2013;40:73-86.

10. Duke WW. The relation of blood platelets to hemorrhagic disease. Description of a method for determining the bleeding time and the coagulation time and report of three cases of hemorrahagic disease relieved by blood transfusion. JAMA. 1910;55:1185-1192.

11. Rodgers RP, Levin J. A critical reappraisal of the bleeding time. Semin Thromb Hemost. 1990;16:1-20.

12. Born GV. Aggregation of blood platelets by adenosine diphosphate and its reversal. Nature. 1962;194:927-929.

13. Zhou L, Schmaier AH. Platelet aggregation testing in platelet-rich plasma: description of procedures with the aim to develop standards in the field. Am J Clin Pathol. 2005;123:172-183.

14. Cardinal DC, Flower RJ.The electronic aggregometer: a novel device for assessing platelet behavior in blood. J Pharmacol Methods. 1980;3: 135-158.

15. Michelson AD. Evaluation of platelet function by flow cytometry. Pathophysiol Haemost Thromb. 2006;35:67-82.

16. Holmsen H, Holmsen I, Bernhardsen A. Microdetermination of adenosine diphosphate and adenosine triphosphate in plasma with the firefly luciferase system. Anal Biochem. 1966;17:456-473.

17. Collet JP, Montalescot G. Platelet function testing and implications for clinical practice. J Cardiovasc Pharmacol Ther. 2009;14:157-169.

18. Bonello L, Tantry US, Marcucci R, et al. Consensus and future directions on the definition of high on-treatment platelet reactivity to adenosine diphosphate. J Am Coll Cardiol. 2010;56:919-933.

19. Darling CE, Sala Mercado JA, Quiroga-Castro W, et al. Point-of-care assessment of platelet reactivity in the emergency department may facilitate rapid rule-out of acute coronary syndromes: a prospective cohort pilot feasibility study. BMJ Open. 2014;4(1):e003883.

20. Quick AJ. The bleeding time as a test of hemostatic function. Am J Clin Pathol. 1975;64:87-94.

21. Peterson P, Hayes TE, Arkin CF, et al. The preoperative bleeding time test lacks clinical benefit: College of American Pathologists' and American Society of Clinical Pathologists' position article. Arch Surg. 1998;133:134-139.

22. Gimple LW, Gold HK, Leinbach RC, et al. Correlation between template bleeding times and spontaneous bleeding during treatment of acute myocardial infarction with recombinant tissue-type plasminogen activator. Circulation. 1989;80:581-588. 
23. Jakubowski JA, Matsushima N, Asai F, et al. A multiple dose study of prasugrel (CS-747), a novel thienopyridine P2Y12 inhibitor, compared with clopidogrel in healthy humans. Br J Clin Pharmacol. 2007;63: 421-430.

24. O'Brien JM. Platelet aggregation. II. Some results from a new method of study. J Clin Pathol. 1962;15:452-458.

25. Kottke-Marchant K, Corcoran G. The laboratory diagnosis of platelet disorders. Arch Pathol Lab Med. 2002;126:133-146.

26. Hayward CP. Diagnostic approach to platelet function disorders. Transfus Apher Sci. 2008;38:65-76.

27. Hayward CP, Pai M, Liu Y, et al. Diagnostic utility of light transmission platelet aggregometry: results from a prospective study of individuals referred for bleeding disorder assessments. JThromb Haemost. 2009; 7 : 676-684.

28. Podda G, Femia EA, Pugliano M, Cattaneo M. Congenital defects of platelets function. Platelets. 2012;23:552-563.

29. Gadisseur A, Hermans C, Berneman Z, Schroyens W, Deckmyn H, Michiels JJ. Laboratory diagnosis and molecular classification of von Willebrand disease. Acta Haematol. 2009;121:71-84.

30. Breet NJ, van Werkum JW, Bouman HJ, et al. Comparison of platelet function tests in predicting clinical outcome in patients undergoing coronary stent implantation. JAMA. 2010;303:754-762.

31. Buonamici P, Marcucci R, Migliorini A, et al. Impact of platelet reactivity after clopidogrel administration on drug-eluting stent thrombosis. J Am Coll Cardiol. 2007;49:2312-2317.

32. Chen WH, Cheng X, Lee PY, et al. Aspirin resistance and adverse clinical events in patients with coronary artery disease. Am J Med. 2007;120:631-635.

33. Lev EI. Aspirin resistance transient laboratory finding or important clinical entity? J Am Coll Cardiol. 2009;53:678-680.

34. Paniccia R, Antonucci E, Maggini N, et al. Light transmittance aggregometry induced by different concentrations of adenosine diphosphate to monitor clopidogrel therapy: a methodological study. Ther Drug Monit. 2011;33:94-98.

35. Femia EA, Pugliano M, Podda G, Cattaneo M. Comparison of different procedures to prepare platelet-rich plasma for studies of platelet aggregation by light transmission aggregometry. Platelets. 2012;23: 7-10.

36. Christie DJ, Avari T, Carrington LR, et al. Platelet Function Testing by Aggregometry: Approved Guideline. Wayne, PA: Clinical and Laboratory Standards Institute; 2008:1-45.

37. Hayward CP, Moffat KA, Raby A, et al. Development of North American consensus guidelines for medical laboratories that perform and interpret platelet function testing using light transmission aggregometry. Am J Clin Pathol. 2010;134:955-963.

38. Harrison P, Mackie I, Mumford A, et al. Guidelines for the laboratory investigation of heritable disorders of platelet function. Br J Haematol. 2011;155:30-44.

39. Cattaneo M, Cerletti C, Harrison P, et al. Recommendations for the standardization of light transmission aggregometry: a consensus of the working party from the Platelet Physiology Subcommittee of SSC/ ISTH. J Thromb Haemost. 2013;11:1183-1189.

40. Mackie IJ, Jones R, Machin SJ. Platelet impedance aggregation in whole blood and its inhibition by antiplatelet drugs. J Clin Pathol. 1984;37: 874-878.

41. Tóth O, Calatzis A, Penz S, Losonczy H, Siess W. Multiple electrode aggregometry: a new device to measure platelet aggregation in whole blood. Thromb Haemost. 2006;96(6):781-788.

42. Paniccia R, Antonucci E, Maggini N, et al. Assessment of platelet function on whole blood by multiple electrode aggregometry in high-risk patients with coronary artery disease receiving antiplatelet therapy. Am J Clin Pathol. 2009;131:834-842.

43. Paniccia R, Antonucci E, Maggini N, et al. Comparison of methods for monitoring residual platelet reactivity after clopidogrel by point-of-care tests on whole blood in high-risk patients. Thromb Haemost. 2010;104: 287-292.

44. Sibbing D, Braun S, Morath T, et al. Platelet reactivity after clopidogrel treatment assessed with point-of-care analysis and early drug-eluting stent thrombosis. J Am Coll Cardiol. 2009;53:849-856.
45. Sibbing D, Morath T, Braun S, et al. Clopidogrel response status assessed with Multiplate point-of-care analysis and the incidence and timing of stent thrombosis over six months following coronary stenting. Thromb Haemost. 2010;103:151-159.

46. Beynon C, Sakowitz OW, Unterberg AW. Multiple electrode aggregometry in antiplatelet-related intracerebral haemorrhage. J Clin Neurosci. 2013;20:1805-1806.

47. Würtz M, Hvas AM, Christensen KH, Rubak P, Kristensen SD, Grove EL. Rapid evaluation of platelet function using the Multiplate ${ }^{\circledR}$ Analyzer. Platelets. 2014;25(8):628-633.

48. Park Y, Jeong YH, Kim IS, et al. The concordance and correlation of measurements by multiple electrode and light transmittance aggregometries based on the pre-defined cutoffs of high and low on-treatment platelet reactivity. Platelets. 2012;23:290-298.

49. Kong R, Trimmings A, Hutchinson N, et al. Consensus recommendations for using the Multiplate ${ }^{\circledR}$ for platelet function monitoring before cardiac surgery. Int J Lab Hematol. Epub July 23, 2014.

50. Bolliger D, Dell-Kuster S, Seeberger MD, et al. Impact of loss of highmolecular-weight von Willebrand factor multimers on blood loss after aortic valve replacement. Br J Anaesth. 2012;108:754-762.

51. Morel-Kopp MC, Aboud M, Tan CW, Kulathilake C, Ward C. Whole blood impedance aggregometry detects heparin-induced thrombocytopenia antibodies. Thromb Res. 2010;125:e234-e239.

52. Sibbing D, Schulz S, Braun S, et al. Antiplatelet effects of clopidogrel and bleeding in patients undergoing coronary stent placement. JThromb Haemost. 2010;8:250-256.

53. Solomon C, Hartmann J, Osthaus A, et al. Platelet concentrates transfusion in cardiac surgery in relation to preoperative point-of-care assessment of platelet adhesion and aggregation. Platelets. 2010;21: 221-228.

54. Tantry US, Bonello L, Aradi D, et al. Consensus and update on the definition of on-treatment platelet reactivity to adenosine diphosphate associated with ischemia and bleeding. J Am Coll Cardiol. 2013;62: 2261-2273.

55. Ranucci M, Baryshnikova E, Soro G, Ballotta A, De Benedetti D, Conti D; Surgical and Clinical Outcome Research (SCORE) Group. Multiple electrode whole-blood aggregometry and bleeding in cardiac surgery patients receiving thienopyridines. Ann Thorac Surg. 2011;91: 123-129.

56. Malek LA, Klopotowski M, Spiewak M, et al. Platelet reactivity and intramyocardial hemorrhage in patients with ST-segment elevation myocardial infarction. Clin Appl Thromb Hemost. 2013;20:553-558.

57. Rahe-Meyer N, Winterhalter M, Boden A, et al. Platelet concentrates transfusion in cardiac surgery and platelet function assessment by multiple electrode aggregometry. Acta Anaesthesiol Scand. 2009;53: $168-175$.

58. Görlinger K, Shore-Lesserson L, Dirkmann D, Hanke AA, RaheMeyer N, Tanaka KA. Management of hemorrhage in cardiothoracic surgery. J Cardiothorac Vasc Anesth. 2013;27(Suppl 4):S20-S34.

59. Fritsma GA. Platelet function testing: aggregometry and lumiaggregometry. Clin Lab Sci. 2007;20:32-37.

60. White MM, Foust JT, Mauer AM, Robertson JT, Jennings LK. Assessment of lumiaggregometry for research and clinical laboratories. Thromb Haemost. 1992;67:572-577.

61. Cattaneo M. Light transmission aggregometry and ATP release for the diagnostic assessment of platelet function. Semin Thromb Hemost. 2009;35:158-167.

62. Pai M, Wang G, Moffat KA, et al. Diagnostic usefulness of a lumiaggregometer adenosine triphosphate release assay for the assessment of platelet function disorders. Am J Clin Pathol. 2011;136:350-358.

63. Hayward CP, Rao AK, Cattaneo M. Congenital platelet disorders: overview of their mechanisms, diagnostic evaluation and treatment. Haemophilia. 2006;12(Suppl 3):128-136.

64. Pai M, Hayward CP. Diagnostic assessment of platelet disorders: what are the challenges to standardization? Semin Thromb Hemost. 2009;35: $131-138$.

65. McGlasson DL, Fritsma GA. Whole blood platelet aggregometry and platelet function testing. Semin Thromb Hemost. 2009;35:168-180. 
66. Buyukasik Y, Goker H, Buyukasik NS, Sayinalp N, Haznedaroglu IC, Ozcebe OI. Effect of platelet count on secretion capacity: formulization and use of the formulae for evaluation of platelet secretion in thrombocytopenic patients. Blood Coagul Fibrinolysis. 2008;19:633-637.

67. Glembotsky AC, Bluteau D, Espasandin YR, et al. Mechanisms underlying platelet function defect in a pedigree with familial platelet disorder with a predisposition to acute myelogenous leukemia: potential role for candidate RUNX1 targets. J Thromb Haemost. 2014;12: 761-772.

68. Smith JW, Steinhubl SR, Lincoff AM, et al. Rapid platelet-function assay: an automated and quantitative cartridge-based method. Circulation. 1999;99:620-625.

69. Steinhubl SR, Talley JD, Braden GA, et al. Point-of-care measured platelet inhibition correlates with a reduced risk of an adverse cardiac event after percutaneous coronary intervention: results of the GOLD (AU-Assessing Ultegra) multicenter study. Circulation. 2001;103(21): 2572-2578.

70. Harrison P, Segal H, Blasbery K, Furtado C, Silver L, Rothwell PM. Screening for aspirin responsiveness after transient ischemic attack and stroke: comparison of 2 point-of-care platelet function tests with optical aggregometry. Stroke. 2005;36:1001-1005.

71. Paniccia R, Antonucci E, Gori AM, et al. Comparison of different methods to evaluate the effect of aspirin on platelet function in highrisk patients with ischemic heart disease receiving dual antiplatelet treatment. Am J Clin Pathol. 2007;128:143-149.

72. Paniccia R, Antonucci E, Gori AM, et al. Different methodologies for evaluating the effect of clopidogrel on platelet function in high-risk coronary artery disease patients. J Thromb Haemost. 2007;5: 1839-1847.

73. Breet NJ, van Werkum JW, Bouman HJ, et al. High on-treatment platelet reactivity to both aspirin and clopidogrel is associated with the highest risk of adverse events following percutaneous coronary intervention. Heart. 2011;97:983-990.

74. Marcucci R, Gori AM, Paniccia R, et al. Cardiovascular death and nonfatal myocardial infarction in acute coronary syndrome patients receiving coronary stenting are predicted by residual platelet reactivity to ADP detected by a point-of-care assay: a 12-month follow-up. Circulation. 2009;119:237-242.

75. Price MJ, Endemann S, Gollapudi RR, et al. Prognostic significance of post-clopidogrel platelet reactivity assessed by a point-of-care assay on thrombotic events after drug-eluting stent implantation. Eur Heart $J$. 2008;29:992-1000.

76. Jeong YH, Bliden KP, Antonino MJ, Park KS, Tantry US, Gurbel PA. Usefulness of the VerifyNow P2Y12 assay to evaluate the antiplatelet effects of ticagrelor and clopidogrel therapies. Am Heart J. 2012;164: $35-42$.

77. Angiolillo DJ, Curzen N, Gurbel P, et al. Pharmacodynamic evaluation of switching from ticagrelor to prasugrel in patients with stable coronary artery disease: results of the SWAP-2 Study (Switching Anti Platelet-2). J Am Coll Cardiol. 2014;63:1500-1509.

78. Rosengart TK, Romeiser JL, White LJ, et al. Platelet activity measured by a rapid turnaround assay identifies coronary artery bypass grafting patients at increased risk for bleeding and transfusion complications after clopidogrel administration. J Thorac Cardiovasc Surg. 2013;146: 1259-1266.

79. Yu PJ, Cassiere HA, Dellis SL, Manetta F, Stein J, Hartman AR. P2Y12 platelet function assay for assessment of bleeding risk in coronary artery bypass grafting. J Card Surg. 2014;29:312-316.

80. Campbell J, Ridgway H, Carville D. Plateletworks: a novel point of care platelet function screen. Mol Diagn Ther. 2008;12:253-258.

81. Lennon MJ, Gibbs NM, Weightman WM, McGuire D, Michalopoulos N. A comparison of Plateletworks and platelet aggregometry for the assessment of aspirin-related platelet dysfunction in cardiac surgical patients. $J$ Cardiothorac Vasc Anesth. 2004;18:136-140.

82. Craft RM, Chavez JJ, Snider CC, Muenchen RA, Carroll RC. Comparison of modified Thrombelastograph and Plateletworks whole blood assays to optical platelet aggregation for monitoring reversal of clopidogrel inhibition in elective surgery patients. $J$ Lab Clin Med. 2005;145:309-315.
83. White MM, Krishnan R, Kueter TJ, Jacoski MV, Jennings LK. The use of the point of care Helena ICHOR/Plateletworks and the Accumetrics Ultegra RPFA for assessment of platelet function with GPIIB-IIIa antagonists. J Thromb Thrombolysis. 2004;18:163-169.

84. Dalén M, van der Linden J, Lindvall G, Ivert T. Correlation between point-of-care platelet unction testing and bleeding after coronary artery surgery. Scand Cardiovasc J. 2012;46:32-38.

85. van Werkum W, Kleibeuker M, Postma S, et al. A comparison between the Plateletworks ${ }^{\mathrm{TM}}$-assay and light transmittance aggregometry for monitoring the inhibitory effects of clopidogrel. Int J Cardiol. 2010;140:123-126.

86. Kundu SK, Heilmann EJ, Sio R, Garcia C, Davidson RM, Ostgaard RA. Description of an in vitro platelet function analyzer - PFA-100. Semin Thromb Hemost. 1995;21(Suppl 2): S106-S112.

87. Koessler J, Ehrenschwender M, Kobsar A, Brunner K. Evaluation of the new INNOVANCE ${ }^{\circledR}$ PFA P2Y cartridge in patients with impaired primary haemostasis. Platelets. 2012;23:571-578.

88. Favaloro EJ. Clinical application of the PFA-100. Curr Opin Hematol. 2002;9:407-415.

89. Michelson AD, Frelinger AL 3rd, Furman MI. Current options in platelet function testing. Am J Cardiol. 2006;98:4N-10N.

90. Harrison P. The role of PFA-100 testing in the investigation and management of haemostatic defects in children and adults. Br J Haematol. 2005; 130:3-10.

91. Hayward CP, Harrison P, Cattaneo M, Ortel TL, Rao AK. Platelet function analyzer (PFA)-100 closure time in the evaluation of platelet disorders and platelet function. J Thromb Haemost. 2006;4:312-319.

92. Homoncik M, Jilma B, Hergovich N, Stohlawetz P, Panzer S, Speiser W. Monitoring of aspirin (ASA) pharmacodynamics with the platelet function analyzer PFA-100. Thromb Haemost. 2000;83:316-321.

93. Marcucci R, Paniccia R, Antonucci E, et al. Residual platelet reactivity is an independent predictor of myocardial injury in acute myocardial infarction patients on antiaggregant therapy. Thromb Haemost. 2007;98:844-851.

94. Edwards A, Jakubowski JA, Rechner AR, Sugidachi A, Harrison P. Evaluation of the INNOVANCE PFA P2Y test cartridge: sensitivity to P2Y(12) blockade and influence of anticoagulant. Platelets. 2012;23: 106-115.

95. Chakroun T, Gerotziafas G, Robert F, et al. In vitro aspirin resistance detected by PFA-100 closure time: pivotal role of plasma von Willebrand factor. Br J Haematol. 2004;124:80-85.

96. Mannini L, Marcucci R, Paniccia R, et al. Erythrocyte deformability and white blood cell count are associated with aspirin resistance in high-risk vascular patients. Clin Hemorheol Microcirc. 2006;35:175-181.

97. Gianetti J, Parri MS, Sbrana S, et al. Platelet activation predicts recurrent ischemic events after percutaneous coronary angioplasty: a 6 months prospective study. Thromb Res. 2006;118:487-493.

98. Hovens MM, Snoep JD, Eikenboom JC, van der Bom JG, Mertens BJ, Huisman MV. Prevalence of persistent platelet reactivity despite use of aspirin: a systematic review. Am Heart J. 2007;153:175-181.

99. Marcucci R, Paniccia R, Antonucci E, et al. Usefulness of aspirin resistance after percutaneous coronary intervention for acute myocardial infarction in predicting one-year major adverse coronary events. Am J Cardiol. 2006;98:1156-1159.

100. Reny JL, De Moerloose P, Dauzat M, Fontana P. Use of the PFA-100 closure time to predict cardiovascular events in aspirin-treated cardiovascular patients: a systematic review and meta-analysis. $J$ Thromb Haemost. 2008;6:444-450.

101. Crescente M, Di Castelnuovo A, Iacoviello L, Vermylen J, Cerletti C, de Gaetano G. Response variability to aspirin as assessed by the platelet function analyzer (PFA)-100. A systematic review. Thromb Haemost. 2008;99:14-26.

102. Koscielny J, von Tempelhoff GF, Ziemer S, et al. A practical concept for preoperative management of patients with impaired primary hemostasis. Clin Appl Thromb Hemost. 2004;10:155-166.

103. Rechner AR. Platelet function testing in clinical diagnostics. Hamostaseologie. 2011;31:79-87. 
104. Raman S, Silverman NA. Clinical utility of the platelet function analyzer (PFA-100) in cardiothoracic procedures involving extracorporeal circulation. J Thorac Cardiovasc Surg. 2001;122:190-191.

105. Cammerer U, Dietrich W, Rampf T, Braun SL, Richter JA. The predictive value of modified computerized thromboelastography and platelet function analysis for postoperative blood loss in routine cardiac surgery. Anesth Analg. 2003;96:51-57.

106. Sucker C, Litmathe J, Feindt P, Zotz R. Platelet function analyzer (PFA-100) as a useful tool for the prediction of transfusion requirements during aortic valve replacement. Thorac Cardiovasc Surg. 2011;59:233-236.

107. Steinlechner B, Zeidler P, Base E, et al. Patients with severe aortic valve stenosis and impaired platelet function benefit from preoperative desmopressin infusion. Ann Thorac Surg. 2011;91:1420-1426.

108. Fries D, Innerhofer P, Streif W, et al. Coagulation monitoring and management of anticoagulation during cardiac assist device support. Ann Thorac Surg. 2003;76:1593-1597.

109. Chauleur C, Cochery-Nouvellon E, Mercier E, et al. Some hemostasis variables at the end of the population distributions are risk factors for severe postpartum hemorrhages. J Thromb Haemost. 2008;6: 2067-2074.

110. Philipp CS, Miller CH, Faiz A, et al. Screening women with menorrhagia for underlying bleeding disorders: the utility of the platelet function analyser and bleeding time. Haemophilia. 2005;11:497-503.

111. Varon D, Dardik R, Shenkman B, et al. A new method for quantitative analysis of whole blood platelet interaction with extracellular matrix under flow conditions. Thromb Res. 1997;85:283-294.

112. Anand SX, Kim MC, Kamran M, et al. Comparison of platelet function and morphology in patients undergoing percutaneous coronary intervention receiving bivalirudin versus unfractionated heparin versus clopidogrel pretreatment and bivalirudin. Am J Cardiol. 2007;100: 417-424.

113. Shenkman B, Matetzky S, Fefer P. Variable responsiveness to clopidogrel and aspirin among patients with acute coronary syndrome as assessed by platelet function tests. Thromb Res. 2008;122:336-345.

114. Yamamoto J, Yamashita T, Ikarugi H, et al. Görög thrombosis test: a global in-vitro test of platelet function and thrombolysis. Blood Coagul Fibrinolysis. 2003;14:31-39.

115. Yamamoto J, Inoue N, Otsui K, Ishii H, Gorog DA. Global thrombosis test (GTT) can detect major determinants of haemostasis including platelet reactivity, endogenous fibrinolytic and thrombin generating potential. Thromb Res. 2014;133:919-926.

116. Saraf S, Wellsted D, Sharma S, Gorog DA. Shear-induced global thrombosis test of native blood: pivotal role of ADP allows monitoring of P2Y12 antagonist therapy. Thromb Res. 2009;124:447-451.

117. Saraf S, Christopoulos C, Salha IB, Stott DJ, Gorog DA. Impaired endogenous thrombolysis in acute coronary syndrome patients predicts cardiovascular death and nonfatal myocardial infarction. J Am Coll Cardiol. 2010;55:2107-2115.

118. Gorog DA, Fuster V. Platelet function tests in clinical cardiology: unfulfilled expectations. J Am Coll Cardiol. 2013;61:2115-2129.

119. Rosser G, Tricoci P, Morrow D, et al. PAR-1 antagonist vorapaxar favorably improves global thrombotic status in patients with coronary disease. J Thromb Thrombolysis. 2014;38:423-429.

120. Luddington RJ. Thrombelastography/thromboelastometry. Clin Lab Haematol. 2005;27:81-90.

121. Ganter MT, Hofer CK. Coagulation monitoring: current techniques and clinical use of viscoelastic point-of-care coagulation devices. Anesth Analg. 2008;106:1366-1375.

122. Görlinger K, Dirkmann D, Solomon C, Hanke AA. Fast interpretation of thromboelastometry in non-cardiac surgery: reliability in patients with hypo-, normo-, and hypercoagulability. Br J Anaesth. 2013;110: 222-230.

123. Welsby IJ, Jiao K, Ortel TL, et al. The kaolin-activated Thrombelastograph predicts bleeding after cardiac surgery. J Cardiothorac Vasc Anesth. 2006;20:531-535.

124. Bolliger D, Tanaka KA. Roles of thrombelastography and thromboelastometry for patient blood management in cardiac surgery. Transfus Med Rev. 2013;27:213-220.
125. Dirkmann D, Görlinger K, Dusse F, Kottenberg E, Peters J. Early thromboelastometric variables reliably predict maximum clot firmness in patients undergoing cardiac surgery: a step towards earlier decision making. Acta Anaesthesiol Scand. 2013;57:594-603.

126. Armstrong S, Fernando R, Ashpole K, Simons R, Columb M. Assessment of coagulation in the obstetric population using ROTEM $^{\circledR}$ thromboelastometry. Int J Obstet Anesth. 2011;20: 293-298.

127. Oudghiri M, Keita H, Kouamou E, et al. Reference values for rotation thromboelastometry $\left(\right.$ ROTEM $\left.^{\circledR}\right)$ parameters following non-haemorrhagic deliveries. Correlations with standard haemostasis parameters. Thromb Haemost. 2011;106:176-178.

128. Afshari A, Wikkelsø A, Brok J, Møller AM, Wetterslev J. Thrombelastography (TEG) or thromboelastometry (ROTEM) to monitor haemotherapy versus usual care in patients with massive transfusion. Cochrane Database Syst Rev. 2011;(3):CD007871.

129. Mallaiah S, Barclay P, Harrod I, Chevannes C, Bhalla A. Introduction of an algorithm for ROTEM-guided fibrinogen concentrate administration in majorobstetric haemorrhage. Anaesthesia. Epub October 7, 2014.

130. Johansson PI, Sølbeck S, Genet G, Stensballe J, Ostrowski SR. Coagulopathy and hemostatic monitoring in cardiac surgery: an update. Scand Cardiovasc J. 2012;46:194-202.

131. Johansson PI, Oliveri RS, Ostrowski SR. Hemostatic resuscitation with plasma and platelets in trauma. J Emerg Trauma Shock. 2012;5: $120-125$.

132. Tanaka KA, Bolliger D, Vadlamudi R, Nimmo A. Rotational thromboelastometry (ROTEM)-based coagulation management in cardiac surgery and major trauma. J Cardiothorac Vasc Anesth. 2012;26: 1083-1093.

133. Song JG, Jeong SM, Jun IG, Lee HM, Hwang GS. Five-minute parameter of thromboelastometry is sufficient to detect thrombocytopenia and hypofibrinogenaemia in patients undergoing liver transplantation. Br J Anaesth. 2014;112:290-297.

134. Wang SC, Shieh JF, Chang KY, et al. Thromboelastography-guided transfusion decreases intraoperative blood transfusion during orthotopic liver transplantation: randomized clinical trial. Transplant Proc. 2010;42:2590-2593.

135. Rugeri L, Levrat A, David JS, et al. Diagnosis of early coagulation abnormalities in trauma patients by rotation thrombelastography. J Thromb Haemost. 2007;5:289-295.

136. Wikkelsoe AJ, Afshari A, Wetterslev J, Brok J, Moeller AM. Monitoring patients at risk of massive transfusion with Thrombelastography or Thromboelastometry: a systematic review. Acta Anaesthesiol Scand. 2011;55:1174-1189.

137. Anderson L, Quasim I, Soutar R, Steven M, Macfie A, Korte W. An audit of red cell and blood product use after the institution of thromboelastometry in a cardiac intensive care unit. Transfus Med. 2006;16: 31-39.

138. Spalding GJ, Hartrumpf M, Sierig T, Oesberg N, Kirschke CG, Albes JM. Cost reduction of perioperative coagulation management in cardiac surgery: value of "bedside" thrombelastography (ROTEM). Eur J Cardiothorac Surg. 2007;31:1052-1057.

139. Bowbrick VA, Mikhailidis DP, Stansby G. Value of thromboelastography in the assessment of platelet function. Clin Appl Thromb Hemost. 2003;9:137-142.

140. Tantry US, Bliden KP, Gurbel PA. Overestimation of platelet aspirin resistance detection by thrombelastograph platelet mapping and validation by conventional aggregometry using arachidonic acid stimulation. J Am Coll Cardiol. 2005;46:1705-1709.

141. Hobson AR, Agarwala RA, Swallow RA, Dawkins KD, Curzen NP. Thrombelastography: current clinical applications and its potential role in interventional cardiology. Platelets. 2006;17:509-518.

142. Agarwal S, Coakley M, Reddy K, Riddell A, Mallett S. Quantifying the effect of antiplatelet therapy: a comparison of the platelet function analyzer (PFA-100) and modified thromboelastography (mTEG) with light transmission platelet aggregometry. Anesthesiology. 2006;105: 676-683. 
143. Bochsen L, Wiinberg B, Kjelgaard-Hansen M, Steinbruchel DA, Johansson PI. Evaluation of the TEG platelet mapping assay in blooddonors. Thromb J. 2007;5:3.

144. Cattano D, Altamirano AV, Kaynak HE, et al. Perioperative assessment of platelet function by Thromboelastograph Platelet Mapping in cardiovascular patients undergoing non-cardiac surgery. J Thromb Thrombolysis. 2013;35:23-30.

145. Lang T, Tollnick M, Rieke M. Evaluation of the new device ROTEM ${ }^{\circledR}$ platelet. Poster presented at: 58th Annual Meeting of Society of Thrombosis and Haemostasis Research (GTH2014); February12-15; 2014; Wien, Austria.

146. Michelson AD, Linden MD, Barnard MR, Furman MI, Frelinger AL 3rd. Flow cytometry. In: Michelson AD, editor. Platelets. San Diego, CA: Elsevier/Academic Press; 2007:545-563.

147. Pati HP, Jain S. Flow cytometry in hematological disorders. Indian J Pediatr. 2013;80:772-778.

148. Carubbi C, Masselli E, Gesi M, et al. Cytofluorimetric platelet analysis. Semin Thromb Hemost. 2014;40:88-98.

149. Harrison P, Keeling D. Clinical tests of platelet function. In: MichelsonAD, editor. Platelets. San Diego, CA: Elsevier/Academic Press; 2007: 445-474.

150. Furman MI, Barnard MR, Krueger LA, et al. Circulating monocyteplatelet aggregates are an early marker of acute myocardial infarction. J Am Coll Cardiol. 2001;38:1002-1006.

151. Barnard MR, Linden MD, Frelinger AL, et al. Effects of platelet binding on whole blood flow cytometry assays of monocyte and neutrophil procoagulant activity. J Thromb Haemost. 2005;3: 2563-2570.

152. Robert S, Lacroix R, Poncelet P, et al. High-sensitivity flow cytometry provides access to standardized measurement of small-size microparticles - brief report. Arterioscler Thromb Vasc Biol. 2012;32: 1054-1058.

153. Kienast J, Schmitz G. Flow cytometric analysis of thiazole orange uptake by platelets: a diagnostic aid in the evaluation of thrombocytopenic disorders. Blood. 1990;75:116-121.

154. Furman MI, Krueger LA, Frelinger AL 3rd, et al. GPIIb-IIIa antagonist-induced reduction in platelet surface factor $\mathrm{V} / \mathrm{Va}$ binding and phosphatidylserine expression in whole blood. Thromb Haemost. 2000;84:492-498.

155. Aleil B, Ravanat C, Cazenave JP, Rochoux G, Heitz A, Gachet C. Flow cytometric analysis of intraplatelet VASP phosphorylation for the detection of clopidogrel resistance in patients with ischemic cardiovascular diseases. J Thromb Haemost. 2005;3:85-92.

156. Spurgeon BEJ, Aburima A, Oberprieler NG, Taskén K, Naseem KM. Multiplexed phosphospecific flow cytometry enables large-scale signaling profiling and drug screening in blood platelets. J Thromb Haemost. 2014;12:1733-1743.

157. Linden MD, Furman MI, Frelinger AL, et al. Indices of platelet activation and the stability of coronary artery disease. J Thromb Haemost. 2007;5:761-765.

158. Ferrer-Marin F, Chavda C, Lampa M, Michelson AD, Frelinger AL, Sola-Visner M. Effects of in vitro adult platelet transfusions on neonatal hemostasis. J Thromb Haemost. 2011;9:1020-1028.

159. Middelburg RA, Roest M, Ham J, Coccoris M, Zwaginga JJ, van der Meer PF. Flow cytometric assessment of agonist-induced P-selectin expression as a measure of platelet quality in stored platelet concentrates. Transfusion. 2013;53:1780-1787.

Vascular Health and Risk Management

\section{Publish your work in this journal}

Vascular Health and Risk Management is an international, peerreviewed journal of therapeutics and risk management, focusing on concise rapid reporting of clinical studies on the processes involved in the maintenance of vascular health; the monitoring, prevention and treatment of vascular disease and its sequelae; and the involvement of
160. Grosser T, Fries S, FitzGerald GA. Thromboxane generation. In: Michelson AD, editor. Platelets. San Diego, CA: Elsevier/Academic Press; 2007:565-574.

161. Müller B. Pharmacology of thromboxane A2, prostacyclin and other eicosanoids in the cardiovascular system. Therapie. 1991;46(3): 217-221.

162. FitzGerald GA, Healy C, Daugherty J. Thromboxane A2 biosynthesis in human disease. Fed Proc. 1987;46:154-158.

163. Patrono C. Biosynthesis and pharmacological modulation of thromboxane in humans. Circulation. 1990;8(Suppl 1):I12-I15.

164. DeFilippis AP, Oloyede OS, Andrikopoulou E, et al. Thromboxane $\mathrm{A}(2)$ generation, in the absence of platelet COX-1 activity, in patients with and without atherothrombotic myocardial infarction. Circ J. 2013;77:2786-2792.

165. Hart RG, Leonard AD, Talbert RL, et al. Aspirin dosage and thromboxane synthesis in patients with vascular disease. Pharmacotherapy. 2003;23:579-584.

166. Hedegaard SS, Hvas AM, Grove EL, et al. Optical platelet aggregation versus thromboxane metabolites in healthy individuals and patients with stable coronary artery disease after low-dose aspirin administration. Thromb Res. 2009;124:96-100.

167. Fontana P, Zufferey A, Daali Y, Reny JL. Antiplatelet therapy: targeting the TxA2 pathway. J Cardiovasc Transl Res. 2014;7:29-38.

168. Cerletti C, Dell'Elba G, Manarini S, et al. Pharmacokinetic and pharmacodynamic differences between two low dosages of aspirin may affect therapeutic outcomes. Clin Pharmacokinet. 2003;42:1059-1070.

169. Shen RF, Tai HH. Monoclonal antibodies to thromboxane synthase from porcine lung. Production and application to development of a tandem immunoradiometric assay. J Biol Chem. 1986;261:11585-11591.

170. Ciabattoni G, Maclouf J, Catella F, FitzGerald GA, Patrono C. Radioimmunoassay of 11-dehydrothromboxane B2 in human plasma and urine. Biochim Biophys Acta. 1987;918:293-297.

171. Rogasi PG, Paniccia R, Coppo M, et al. Radioimmunoassay of thromboxane B2 in plasma: methodological modifications. Thromb Res. 1988;51:533-541.

172. Muir AR, McMullin MF, Patterson C, McKeown PP. Assessment of aspirin resistance varies on a temporal basis in patients with ischaemic heart disease. Heart. 2009;95:1225-1229.

173. Gremmel T, Perkmann T, Seidinger D, et al. Differential impact of inflammation on six laboratory assays measuring residual arachidonic acid-inducible platelet reactivity during dual antiplatelet therapy. J Atheroscler Thromb. 2013;20:630-645.

174. Roest M, Reininger A, Zwaginga JJ, King MR, Heemskerk JW. Biorheology Subcommittee of the SSC of the ISTH: flow chamberbased assays to measure thrombus formation in vitro: requirements for standardization. J Thromb Haemost. 2011;9:2322-2324.

175. Van Kruchten R, Cosemans JM, Heemskerk JW. Measurement of whole blood thrombus formation using parallel-plate flow chambers a practical guide. Platelets. 2012;23:229-242.

176. Aslan JE, Itakura A, Gertz JM, McCarty OJ. Platelet shape change and spreading. Methods Mol Biol. 2012;788:91-100.

177. Kirchmaier CM, Pillitteri D. Diagnosis and management of inherited platelet disorders. Transfus Med Hemother. 2010;37:237-246.

178. Ge S, Woo E, White JG, Haynes CL. Electrochemical measurement of endogenous serotonin release from human blood platelets. Anal Chem. 2011;83:2598-2604.

metabolic disorders, particularly diabetes. This journal is indexed on PubMed Central and MedLine. The manuscript management system is completely online and includes a very quick and fair peer-review system, which is all easy to use. Visit http://www.dovepress.com/ testimonials.php to read real quotes from published authors. 